\title{
New alternative for sustainable organic synthesis: a simple way to obtain allylic amines
}

\author{
Claudia G. Adam* , Claudia D. Della Rosa* \\ IQAL (UNL-CONICET), Laboratorio Fisicoquímica Orgánica, Facultad de Ingeniería Química, Universidad \\ Nacional del Litoral. Santiago del Estero 2829. (3000) Santa Fe, Argentina. \\ FAX: +54-342-4571162. *e-mail: cadam@ fiq.unl.edu.ar; cdellaro@ fiq.unl.edu.ar
}

\begin{abstract}
The allylic amines are molecules that acquirer interest as building blocks in the path of synthesis of products with biological activity such as herbicides, antibiotics and insecticides. The methods for obtaining allylic amines are scarce and with a high number of stages. As a consequence, we have the purpose of making reactive systems of dienes and PILs based on alkyl ammonium derivatives that facilitate the obtaining of such precursors through green synthetic strategies.
\end{abstract}

Keywords. Protic ionic liquids, alkylammonium, catalyst, allylic amine

\section{Introduction}

In the last few years, chemists have tried to adapt chemical reactions in order to comply with the principles of green chemistry. ${ }^{1}$ Consequently, our challenge is to use specific behaviors observed in ionic liquids (ILs) and transform them into a benefit on a reactive process. The protic ionic liquid (PILs) are considered a subset of ILs, they have a an available proton on the cation and this key feature, leading to numerous applications including in organic and inorganic synthesis, biological applications, electrochemical applications, lubrication, and as amphiphile self-assembly media. The ethylammonium nitrate (EAN) is the most studied however this, new applications are reported.

In previous work we presented the effect of molecular solvents on the hydrogen bonding present in PILs based-alkylammonium cations derivates of primary, secondary and tertiary amines. We determinate the pKa value of this PILs from Reichardt's dye. We observed that for all PILs analysed the molecular solvent dimethyl sulfoxide (DMSO) increased the pKa 
values, indicating a strong catión-anion interaction and more basic nature of the PILs. Contrary, a molecular solvent as methanol or acetonitrile (AN) with characteristic hydrogen bond donor (HBD), turns these PILs more acidic.

Is known that dual action as catalyst and solvent, conduces to more mild reaction conditions, we have reported this behaviour of protic ionic liquids (PILs) as Ethyl Ammonium Nitrate (EAN). ${ }^{2,3}$

Taking into account this, our goal is to use these conducts of PILs to develop alternative methods of interest in organic synthesis. In this sense, the allilyc amines are molecules that acquirer interest as building blocks in the path of synthesis of products with biological activity such as herbicides, antibiotics and insecticides. The methods for obtaining allylic amines are scarce and with a high number of stages. ${ }^{4}$ As a consequence, we have the purpose of making reactive systems of dienes and PIL base alkyl ammonium that facilitate the obtaining of such precursors through green synthetic strategies. Advantages of these strategies are that they are economic in stages and develop in more benign reaction conditions.

\section{Results and Discussion}

The proposed reactive systems are made up of conjugated dienes and PILs basedalkylammonium cations. The PILs employed in the reactions were: ethylammoniun nitrate (EAN), diethylammonium nitrate (DEAN) and tributylammonium nitrate (TBAN), the ionic liquids were previously synthesized and purified by members of our working group. The conjugated dienes used were 2-methyl-1,3-butadiene, 1-methyl-1,3-cyclopentadiene, furan and tiophene. (Scheme 1). 


\section{Conjugated Dienes}

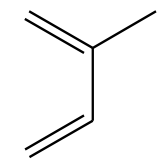

1

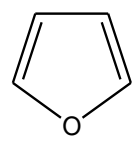

3

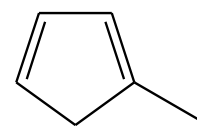

2

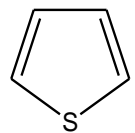

4
Protic Ionic Liquids

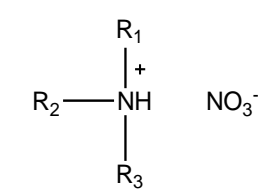

$5 \mathrm{a} \mathrm{R}_{1}=\mathrm{C}_{2} \mathrm{H}_{5} ; \mathrm{R}_{2}=\mathrm{R}_{3}=\mathrm{H}(\mathrm{EA})$

b $\mathrm{R}_{1}=\mathrm{R}_{2}=\mathrm{C}_{2} \mathrm{H}_{5} ; \mathrm{R}_{3}=\mathrm{H}$ (DEA)

c $\mathrm{R}_{1}=\mathrm{R}_{2}=\mathrm{R}_{3}=\mathrm{C}_{4} \mathrm{H}_{9}(\mathrm{TBA})$

\section{Scheme 1}

The experiences were developed in a reactor at atmospheric pressure at $50{ }^{\circ} \mathrm{C}$ for $24 \mathrm{~h}$ with stirring, the procedures were applied to pursue the optimization of the reaction conditions for each pair diene conjugate/ ionic liquid.

The reactions were checked by chromatographic methods. ${ }^{1} \mathrm{H}$ and ${ }^{13} \mathrm{C}$ NMR espectra were recorded with the deuterated solvent as the lock and residual solvent as internal on 300 and $75 \mathrm{MHz}$ FT-spectrometers, respectively; GC-MS analyses were performed in an instrument equipped with a PE-5-type column.IR spectra were recorded from $\mathrm{NaCl}$ cells. The silica gel and neutral alumina used for chromatography were 70-230 mesh.

In the first place were developed reactions using $\mathbf{1}$ as diene conjugate, which was exposed to the different nitrate-based alquilamonica $\mathbf{5 a}, \mathbf{5 b}$ and $\mathbf{5} \mathbf{c}$.

In this direction, for the reaction mixture of $\mathbf{1}$ and EAN was obtained as a single product allylic amine 6 (addition product) with very good yields (78\%). Figure 1.

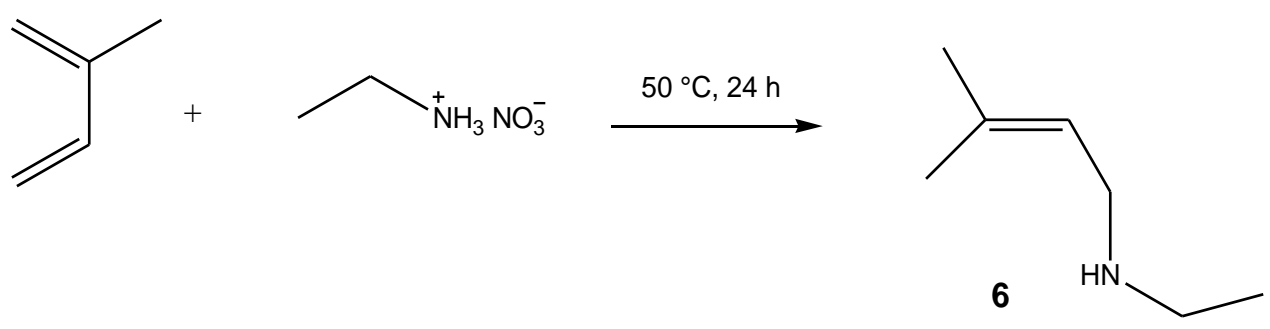

\section{Figure 1}


One of the most notable differences between the chemistry of the conjugated dienes and isolated dienes lies in its electrophilic addition reactions, since in the reactions of conjugated dienes allyl carbocations are involved as intermediaries.

A similar behavior was observed in the reactions developed at $50^{\circ} \mathrm{C}$ using 1 and $\mathrm{DEAN}$, with the difference that the yields of the allylic amine 7 obtained were much smaller (24 hours, $15 \%$; 48 hs, $25 \%$ ) (Figure 2). The reactions of TBAN with diene 1 did not yield product in working conditions employed.

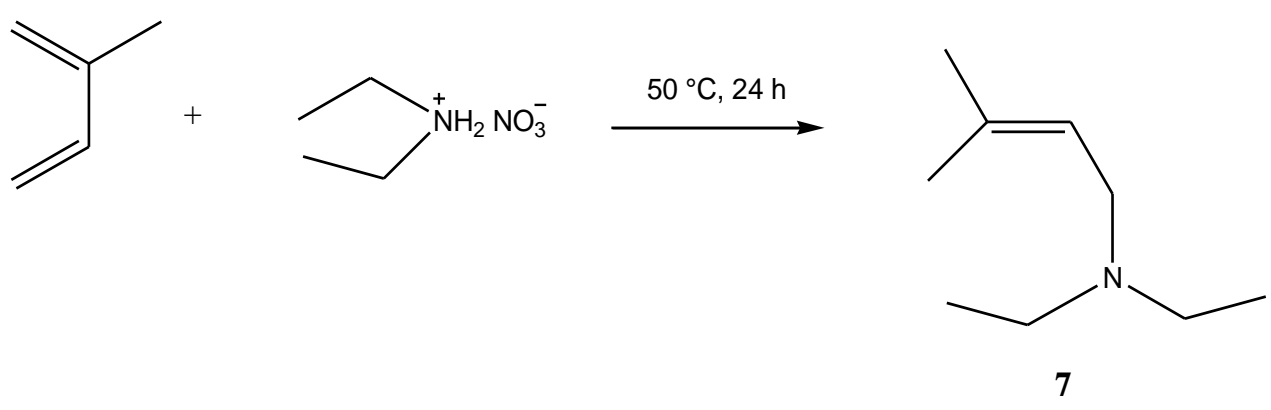

Figure 2

The experiences development with diene 2 and EAN yielded a complex mixture of allylic amines whose perfomance were $60 \%\left(50{ }^{\circ} \mathrm{C}, 24 \mathrm{~h}\right)$ and $70 \%\left(50^{\circ} \mathrm{C}, 48 \mathrm{~h}\right)$.

When 3 was employed as diene with EAN, a isomeric mixture were obtained as principal products.

It was not observed formation of products when $\mathbf{4}$ was used as conjugated diene.

\section{Conclusions}

The results showed that that has been developed new synthetic strategy for obtaining allylic amines from simple molecules and in a single step. This feature puts this method as an alternative in organic synthesis sustainable not only for waste minimization, reagents, solvents, etc. when compared to the conventional synthesis in several stages

\section{Acknowledgments}

This research was supported by CAI+D 2016 PIC 50420150100023LI at Universidad Nacional del Litoral, Santa Fe, Argentina and Convocatoria Investigación Orientada 2016 - 
2010-035-16 Ministerio de Ciencia, Tecnología e Innovación Productiva de la provincia de Santa Fe (ASaCTeI).

\section{References}

1- Anastas, P.T.; Warner, J.C. Green Chemistry: Theory and Practice, Oxford University Press: New York, 1998, p. 30.

2- Adam, C.G. et al., J. Physical Organic Chemistry 2009, 22, 460-465.

3- Adam, C. G. et al. Tetrahedron Letters, 2014, 55, 148-150.

4- Aguilar, E., Joglar, J., Merino, I., Olano, B., Palacios, F., Fustero, S. Tetrahedron, 2000, 56, 8179-8187. 